\title{
Effect of p-Layer and i-Layer Properties on the Electrical Behaviour of Advanced a-Si:H/a-SiGe:H Thin Film Solar Cell from Numerical Modeling Prospect
}

\author{
Peyman Jelodarian and Abdolnabi Kosarian \\ Department of Electrical Engineering, Shahid Chamran University of Ahvaz, Ahvaz 61357-831351, Iran \\ Correspondence should be addressed to Peyman Jelodarian, p.jelodarian@yahoo.com
}

Received 9 August 2011; Revised 26 September 2011; Accepted 30 September 2011

Academic Editor: Leonardo Palmisano

Copyright ( $) 2012$ P. Jelodarian and A. Kosarian. This is an open access article distributed under the Creative Commons Attribution License, which permits unrestricted use, distribution, and reproduction in any medium, provided the original work is properly cited.

\begin{abstract}
The effect of p-layer and i-layer characteristics such as thickness and doping concentration on the electrical behaviors of the a$\mathrm{Si}: \mathrm{H} / \mathrm{a}-\mathrm{SiGe} \mathrm{H}$ thin film heterostructure solar cells such as electric field, photogeneration rate, and recombination rate through the cell is investigated. Introducing Ge atoms to the Si lattice in Si-based solar cells is an effective approach in improving their characteristics. In particular, current density of the cell can be enhanced without deteriorating its open-circuit voltage. Optimization shows that for an appropriate Ge concentration, the efficiency of a-Si:H/a-SiGe solar cell is improved by about $6 \%$ compared with the traditional a-Si:H solar cell. This work presents a novel numerical evaluation and optimization of amorphous silicon double-junction (a-Si:H/a-SiGe:H) thin film solar cells and focuses on optimization of a-SiGe:H midgap single-junction solar cell based on the optimization of the doping concentration of the p-layer, thicknesses of the p-layer and i-layer, and Ge content in the film. Maximum efficiency of $23.5 \%$, with short-circuit current density of $267 \mathrm{~A} / \mathrm{m}^{2}$ and open-circuit voltage of $1.13 \mathrm{~V}$ for double-junction solar cell has been achieved.
\end{abstract}

\section{Introduction}

Hydrogenated amorphous silicon-germanium alloys (aSiGe:H) are widely used in multijunction solar cells, where their main advantage is the capability of shifting the optical band gap to lower energies by increasing the germanium concentration in the film [1-3]. In order to avoid drastic reduction of the short-circuit current $\left(J_{S C}\right)$ in a cell with small thickness, it is necessary to increase absorbance of the material and optimize the cell structure [4]. Using a lower band-gap material such as a-SiGe in the active base region of the cell is a possible approach, owing to its compatibility with the mature Si-based cell process. An appreciable increase of photocurrent $\left(J_{S C}\right)$ in the small band-gap a-SiGe material is highly expected, because of the increased absorption of photons. On the other hand, a drop of the open-circuit voltage $\left(V_{\mathrm{OC}}\right)$, due to the reduction of the SiGe bandgap with increasing Ge concentration $[5,6]$. As a result, a compromise between the cell's parameters is necessary in the optimization procedure. The optimization of band-offset between a-SiGe and a-Si either in the valence band $\left(E_{V}\right)$ or in the conduction band $\left(E_{C}\right)$ can help design a more effective back surface field, where the photogenerated carriers from the highly dislocated surfaces and interfaces are reflected, thus at the backside of the cell the recombination velocity is significantly decreased. The band offset of $E_{V}$ and $E_{C}$ at the a$\mathrm{Si} / \mathrm{SiGe}$ heterointerface is dependent on the Ge concentration in the film. In addition to less surface recombination velocity, the smaller band gap $\left(E_{g}\right)$ in high Ge concentration SiGe film has a larger light absorption coefficient, which can lead to more electron-hole pair generation and higher $J_{\mathrm{SC}}$. Both of them can result in higher cell efficiency of the a-SiGe-based solar cell [4]. The optimization process of a multijunction structure involves both the design of individual junction layers which produces an optimum output power and the design of a series stacked configuration of these junction layers which yields the highest possible overall output current. Figure 1 shows a double-junction structure for a pi-n a-Si solar cell used in this work [7]. 


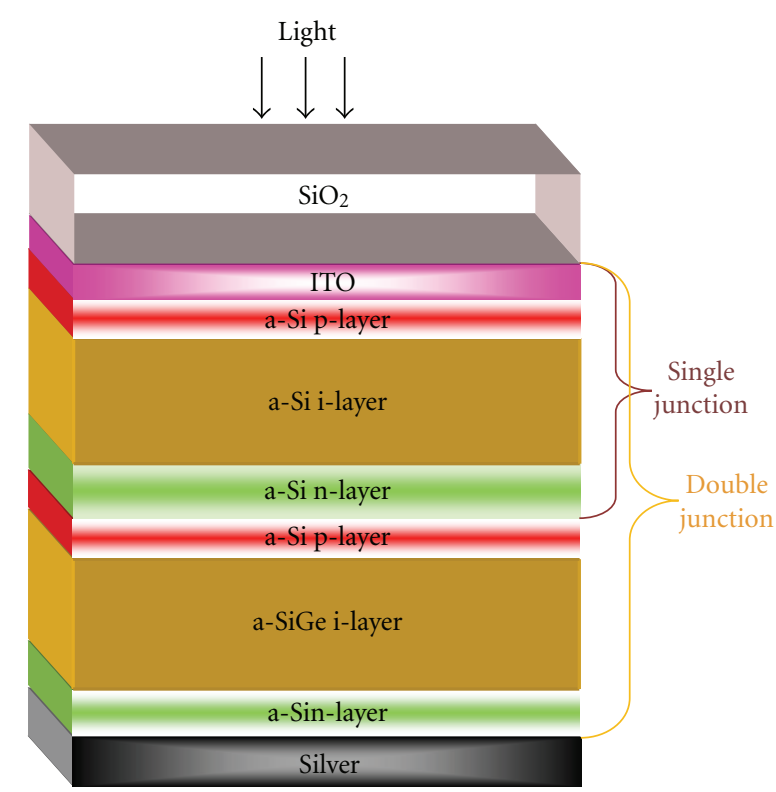

FIgURE 1: The structure of a double junction and the Layers material of simulated double-junction a-Si:H/a-SiGe:H solar cell.

\section{Numerical Modeling}

Referring to its $I-V$ characteristics, the most important parameters of a solar cell are the short-circuit current $\left(J_{S C}\right)$, the open-circuit voltage $\left(V_{\mathrm{OC}}\right)$, fill factor $(\mathrm{FF})$, and efficiency $(\eta)$. The short-circuit current is due to the generation and collection of light-generated carriers. So, ideally, it is equal to the light-generated current, and is the largest current that can flow through the solar cell. However, an appreciable fraction of the generated carriers recombine in the bulk and interface. The recombination losses are characterized by the diffusion length and the minority carrier lifetime in the active region.

Modeling of the device is based on the simultaneous solution of transport equations, such as, Poisson equations, continuity equations, and current density equations for holes and electrons [8]:

$$
\begin{gathered}
-\nabla \cdot \varepsilon \nabla \psi=q \rho, \\
\nabla \cdot J_{p}=q(G-R), \\
\nabla \cdot J_{n}=-q(G-R),
\end{gathered}
$$

where $\varepsilon$ is the dielectric constant, $\psi$ is the homojunction hole potential, $-q$ is the electron charge, $J_{p}$ and $J_{n}$ are the current densities due to transport by hole and electron, respectively, $G$ is the generation rate for carriers, and $R$ is the recombination rate. The net charge carrier density $\rho$ is given by the following expression:

$$
\rho=p-n+n_{T}-p_{T}+N_{\text {tail }}+N_{\mathrm{DS}}
$$

where $p$ and $n$ are the free hole and electron densities, $n_{T}$ and $p_{T}$ are the concentrations of ionized acceptor and donors, $N_{\text {tail }}$ and $N_{\text {DS }}$ are the net charge densities due to the trapping of holes and electrons in tail states and dangling bond states, respectively. The value for $n_{T}$ and $p_{T}$ are calculated from the energy levels and total densities of donors and acceptors and from the spatially varying concentrations of free carriers in the solar cell.

Disordered materials like amorphous Silicon and SiliconGermanium contain a large amount of defect states within the band gap of the material. To accurately model devices made of amorphous silicon, one should use a continuous density of states. The density of defect states (DOSs) is specified with a combination of Gaussian distributions of midgap states and exponentially decaying band tail states $[8,9]$.

Here, it is assumed that the total density of states (DOSs), $g(E)$, is combined of four components: two tail bands (an acceptor-like conduction band and a donor-like valence band), which are modeled by an exponential distribution, and two deep level bands (one donor-like and the other acceptor-like), which are modeled by a Gaussian distribution $[9,10]$ :

$$
g(E)=g_{T D}(E)+g_{T A}(E)+g_{G D}(E)+g_{G A}(E),
$$

where $E$ is the trap energy. The subscripts $(G, T, A, D)$ stand for Gaussian (deep level), tail, acceptor, and donor states, respectively, and $[9,10]$

$$
\begin{aligned}
& g_{T D}(E)=N_{T D} \exp \left[\frac{E_{V}-E}{W_{T D}}\right], \\
& g_{T A}(E)=N_{T A} \exp \left[\frac{E-E_{C}}{W_{T A}}\right], \\
& g_{G A}(E)=N_{G A} \exp \left[-\left[\frac{E_{G A}-E}{W_{G A}}\right]^{2}\right], \\
& g_{G D}(E)=N_{G D} \exp \left[-\left[\frac{E-E_{G D}}{W_{G D}}\right]^{2}\right],
\end{aligned}
$$

where $E$ is the trap energy, $E_{C}$ is the conduction band energy, and $E_{V}$ is the valence band energy.

For exponential tail distributions, the DOS is described by its conduction and valence band edge intercept densities $\left(N_{T D}\right.$ and $\left.N_{T A}\right)$ and by its characteristic decay energy ( $W_{T D}$ and $\left.W_{T A}\right)$. For Gaussian distributions, the DOS is described by its peak energy $\left(E_{G D}\right.$ and $\left.E_{G A}\right)$, its characteristic decay energy $\left(W_{G A}\right.$ and $\left.W_{G D}\right)$, and its total density of states $\left(N_{G D}\right.$ and $\left.N_{G A}\right)$.

The ionized densities of acceptor- and donor-like states $\left(n_{T}\right.$ and $p_{T}$, resp.) are given by:

$$
\begin{aligned}
& n_{T}=n_{T D}+n_{G D}, \\
& p_{T}=p_{T A}+p_{G A},
\end{aligned}
$$

where $p_{T A}, p_{G A}, n_{T D}$, and $n_{G D}$ are as below: 


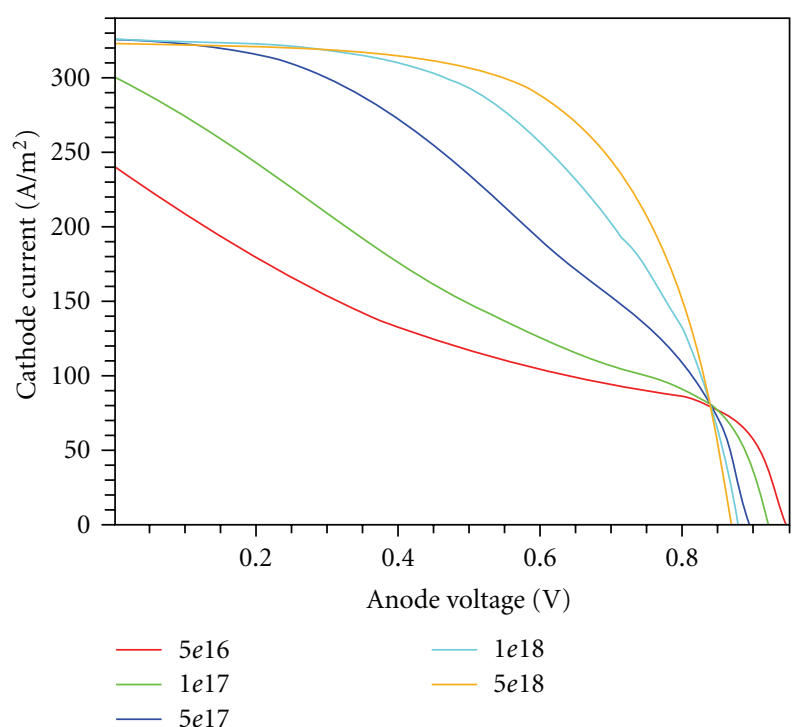

(a)

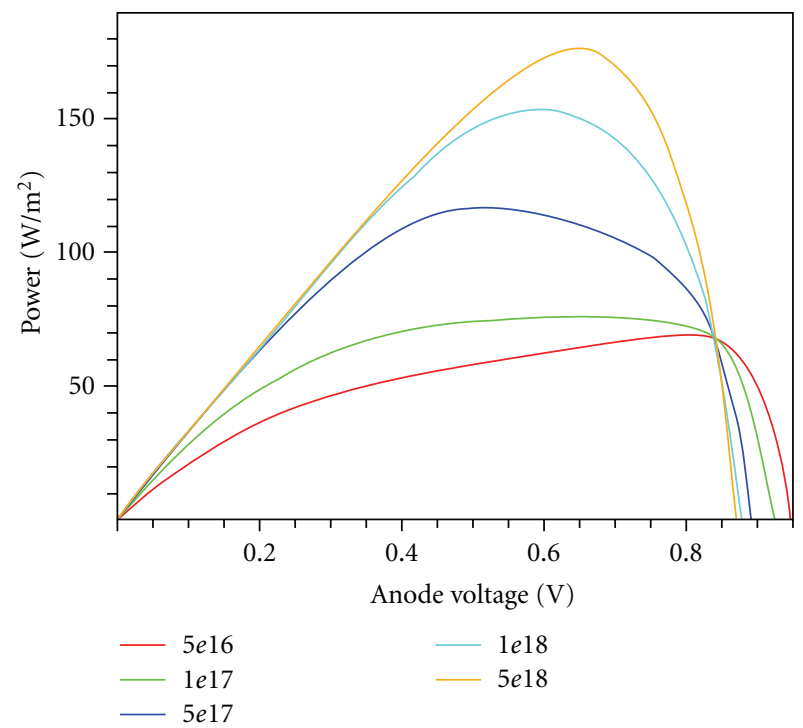

(b)

Figure 2: $I-V$ and $P-V$ curves of the a-SiGe:H single junction solar cell as a function of acceptor concentration in p-layer.

$$
\begin{aligned}
& p_{T A}=\int_{E_{V}}^{E_{C}} g_{T A}(E) \cdot f_{t_{T A}}(E, n, p) d E, \\
& p_{G A}=\int_{E_{V}}^{E_{C}} g_{G A}(E) \cdot f_{t_{G A}}(E, n, p) d E, \\
& n_{T D}=\int_{E_{V}}^{E_{C}} g_{T D}(E) \cdot f_{t_{T D}}(E, n, p) d E, \\
& n_{G D}=\int_{E_{V}}^{E_{C}} g_{G D}(E) \cdot f_{t_{G D}}(E, n, p) d E .
\end{aligned}
$$

where $f_{t_{T A}}(E, n, p)$ and $f_{t_{G A}}(E, n, p)$ are the ionization probabilities for the tail and Gaussian acceptor DOS, while $f_{t_{T D}}(E, n, p)$ and $f_{t_{G D}}(E, n, p)$ are the ionization probabilities for the donors.
TABLE 1: The set of input parameters used in the simulation.

\begin{tabular}{lccc}
\hline Layer & p-layer & i-layer & n-layer \\
\hline Thickness $[\mathrm{nm}]$ & 50 & 800 & 50 \\
Doping concentration $\left[/ \mathrm{cm}^{3}\right]$ & $5 \times 10^{18}$ & $1 \times 10^{14}$ & $3 \times 10^{18}$ \\
Mobility gap $[\mathrm{eV}]$ & 1.8 & 1.5 & 1.8 \\
Electron mobility $\left[\mathrm{cm}^{2} / \mathrm{Vs}\right]$ & 10 & 20 & 20 \\
Hole mobility $\left[\mathrm{cm}^{2} / \mathrm{Vs}\right]$ & 1 & 2 & 2 \\
Effective DOS in CB $\left[/ \mathrm{cm}^{3}\right]$ & $2.5 \times 10^{20}$ & $1 \times 10^{20}$ & $2.5 \times 10^{20}$ \\
Effective DOS in $\mathrm{VB}\left[/ \mathrm{cm}^{3}\right]$ & $2.5 \times 10^{20}$ & $1 \times 10^{20}$ & $2.5 \times 10^{20}$ \\
\hline
\end{tabular}

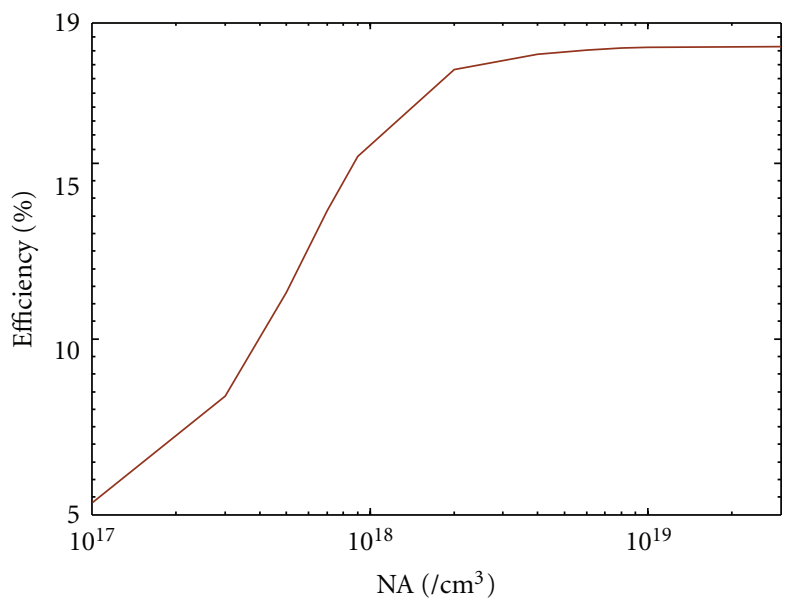

Figure 3: The a-SiGe:H solar cell efficiency as a function of concentration of acceptor in p-layer.

In the $\mathrm{p}-\mathrm{i}-\mathrm{n}$ structure of Figure 1 the p-type a-Si:H layer is highly doped, since its higher conductivity allows more light to pass through to the intrinsic layer. As a result, the open-circuit voltage as well as the short-circuit current could be improved. Moreover, this layer is made thinner than the other layers to give the carriers less opportunity and time to recombine before reaching the intrinsic layer.

Table 1 shows a set of input parameters, which are used in our simulation. The transparent conductive ITO layer has $75 \mathrm{~nm}$ thickness. For a-SiGe:H p-i-n solar cell, it is widely accepted that the most important parameters affecting the device properties are the gap states of the films.

In this work, the AM1.5 spectrum for illumination of samples was used.

\section{Results and Discussion}

The performance of a one-square-meter $\mathrm{p}$-i-n single-junction a-SiGe:H solar cell ( $\mathrm{SiO} 2 / \mathrm{ITO} / \mathrm{p}-\mathrm{a}-\mathrm{Si}: \mathrm{H} / \mathrm{i}-\mathrm{a}-\mathrm{SiGe}: \mathrm{H} / \mathrm{n}-\mathrm{a}-$ $\mathrm{Si}: H /$ Silver$)$, such as short-circuit current $\left(J_{\mathrm{SC}}\right)$, open-circuit voltage $\left(V_{\mathrm{OC}}\right)$, fill factor $(\mathrm{FF})$, conversion efficiency $(\eta)$, and $I-V$ curve, are obtained as a function of doping concentration, atomic percent of Ge in a-SiGe layer and thicknesses of i-layer and p-layer. Also variations of the electrical properties inside the solar cell such as the distribution of photogeneration and recombination rates, and electric field, with variation of layers properties are obtained. 


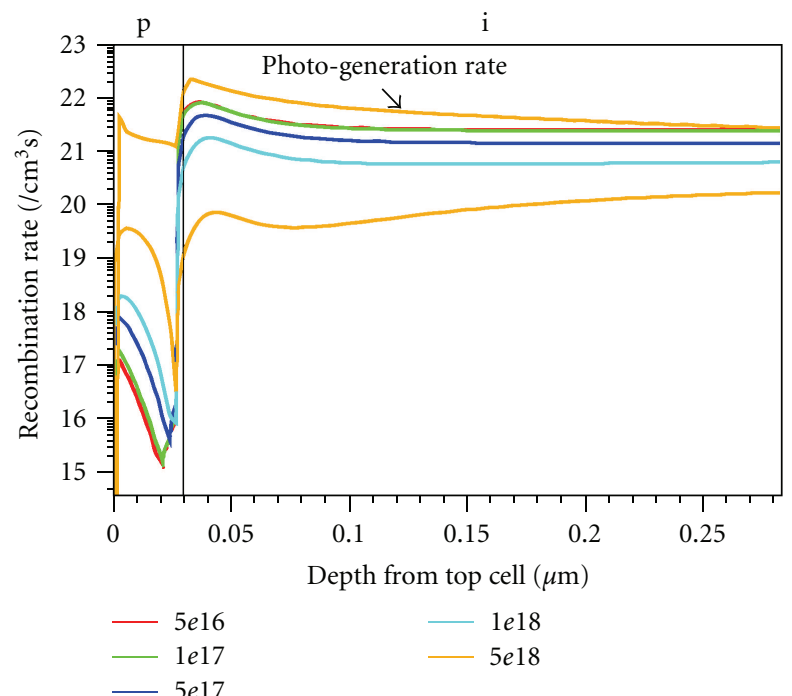

(a)

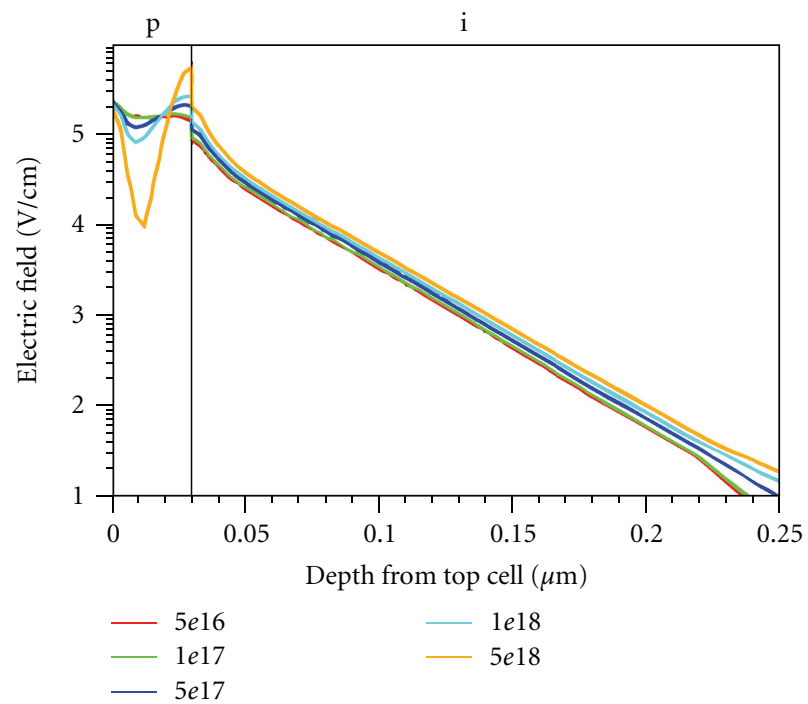

(b)

FIgure 4: Recombination rate and electric field distribution of The a-SiGe:H solar cell device for different acceptor concentrations in p-layer.

In order to be able to collect the maximum number of electron-hole pairs generated by absorbed photons, the electric field at the $\mathrm{p}$-i interface should be as high as possible; however, the recombination rate also increases with increasing the electric field, resulting in a reduction in the efficiency. So, there must be a compromise between the recombination rate and the electric field.

The a-SiGe:H solar cell $I-V$ and $P-V$ curves as a function of p-layer doping concentration are shown in Figure 2.

The a-SiGe:H solar cell efficiency as a function of $\mathrm{p}$ layer doping concentration is shown in Figure 3. The other parameters are the same as in Table 1.

According to Figures 2 and 3, simulation indicates that for the p-layer concentrations larger than $10^{18} \mathrm{~cm}^{-3}$, the cell has a high efficiency due to the drastic increase in

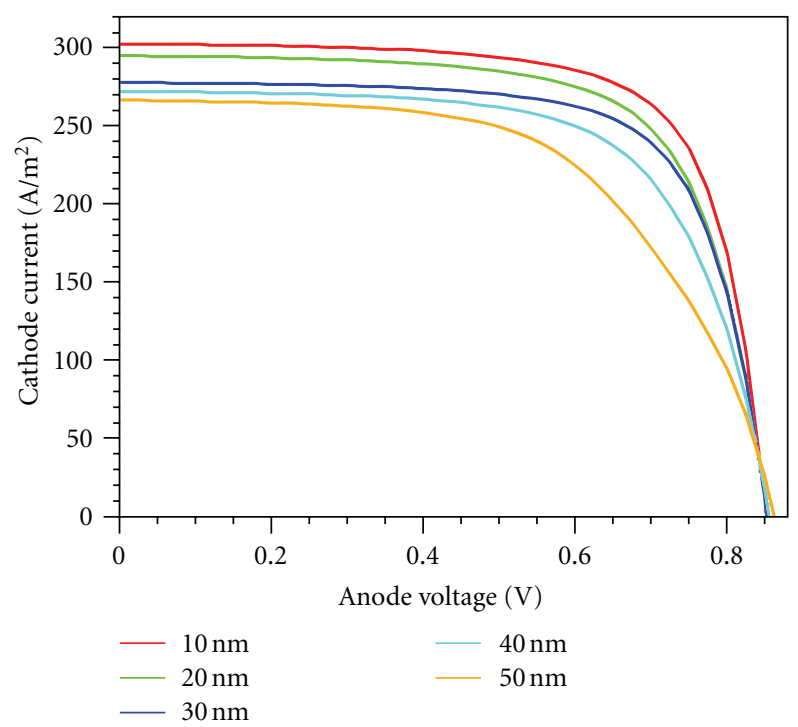

(a)

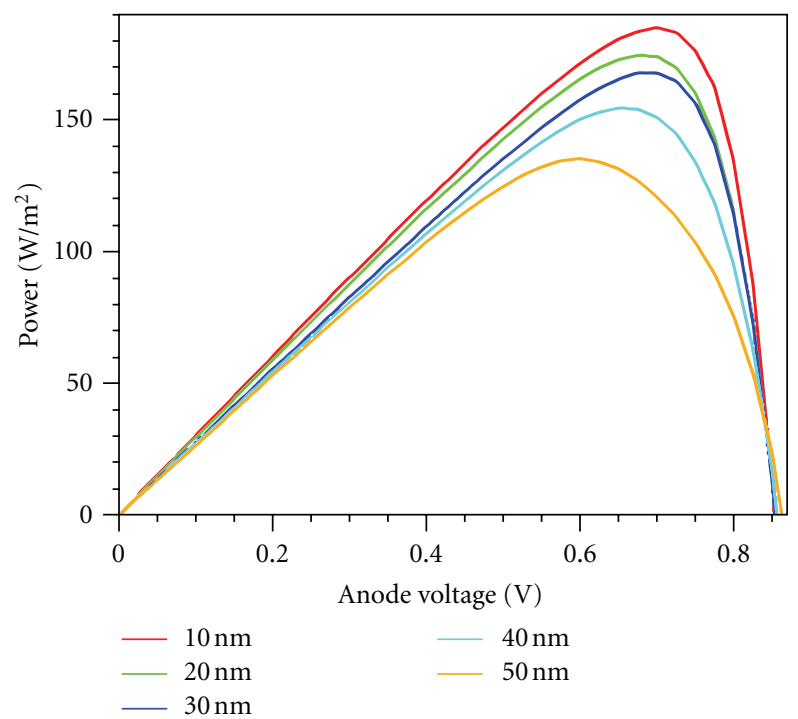

(b)

Figure 5: $I-V$ and $P-V$ curves of the a-SiGe:H single junction solar cell as function of thickness of p-layer.

short circuit current of the device. However, care is needed to achieve such a high acceptor concentration in the film without degrading the film quality.

Figure 4 shows the recombination rate and electric field distribution through the cell as a function of p-layer doping concentration. As shown in figure, $5 \times 10^{18} \mathrm{~cm}^{-3}$ of $\mathrm{p}-$ layer concentration builds the highest electric field at the $\mathrm{p}-\mathrm{i}$ interface that results more carriers collection by ITO layer, but it also has the highest recombination rate in i-layer.

The a-SiGe:H solar cell $I-V$ and $P-V$ curves as a function of p-layer thickness are shown in Figure 5.

The effect of p-layer thickness on the efficiency of the cell is shown in Figure 6. The other parameters used are the same as in Table 1. The thickness of the p-layer was changed from 10 to $90 \mathrm{~nm}$. 


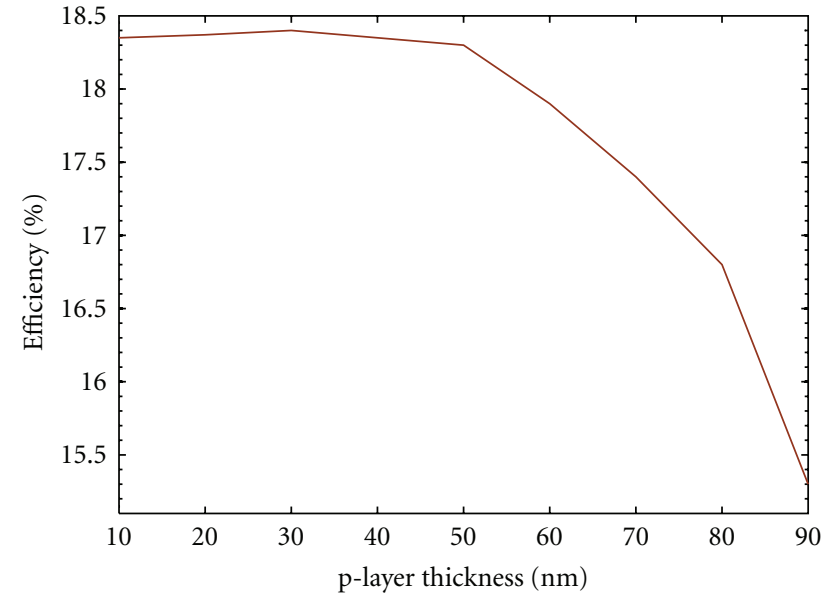

Figure 6: The a-SiGe:H solar cell efficiency as a function of thickness of p-layer.

The photogeneration rate and recombination rate and electric field distribution through the cell as a function of p-layer thickness are shown in Figures 7 and 8, respectively. These Figures show that the cell with thinner p-layer has lower recombination rate in p-layer and high electric field in $\mathrm{p}-\mathrm{i}$ interface that results in higher current density.

The SiGe band-gap, which is engineered by alteration of Ge concentration, is a critical parameter in the SiGe solar cell design. Introducing $\mathrm{Ge}$ atoms to the $\mathrm{Si}$ lattice in Sibased solar cells is an effective approach in improving their characteristics. In particular, current density of the cell can be enhanced without deteriorating its open-circuit voltage. The efficiency of the solar cell as a function of Ge concentration in SiGe layer is shown in Figure 9, where it is changed between 0 and 30 at \%. The other parameters used are the same as in Table 1. Simulation shows that the maximum efficiency of $18.5 \%$ is obtained at the optimized value of Ge concentration of 17 at \%, which shows $6 \%$ improvement in the overall efficiency of the cell compared with the common singlejunction a-Si:H solar cell, Figure 9.

In amorphous thin film $\mathrm{p}-\mathrm{i}-\mathrm{n}$ solar cell, a thick absorber layer (i-layer) can absorb more light to generate electron and hole (carriers); however, a thicker i-layer degrades the drift electric field for carrier transport. On the other hand, a thin $\mathrm{i}$-layer cannot absorb enough light. Thickness of i-layer is a key parameter that can limit the performance of amorphous thin film solar cells. The a-SiGe:H solar cell efficiency as a function of the i-layer thickness are shown in Figure 10. The other parameters used are the same as in Table 1. As shown in the figure, maximum efficiency is obtained at the $0.8 \mathrm{um}$ of thickness of i-layer.

Based on the optimized a-Si:H/SiGe:H single-junction solar cell, described previously, a double-junction solar cell (Figure 1) has been designed. $I-V$ and $P-V$ characteristics of the optimized single- and double-junction solar cells are shown in Figure 11. As you can see the current density of double-junction solar cell is lower than single-junction solar cell, because of current limitation of a-Si:H solar cell. The figures show that for double-junction cell the short-circuit

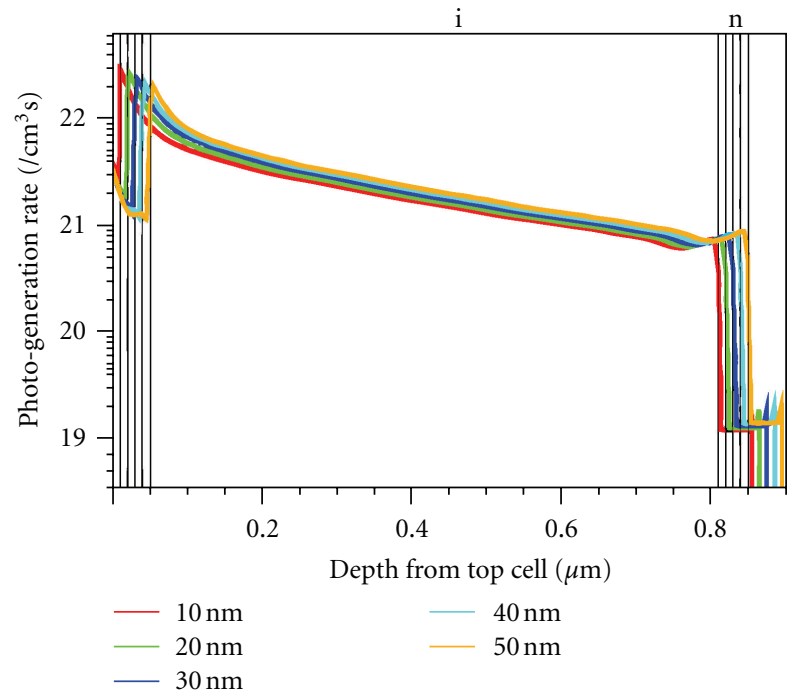

(a)

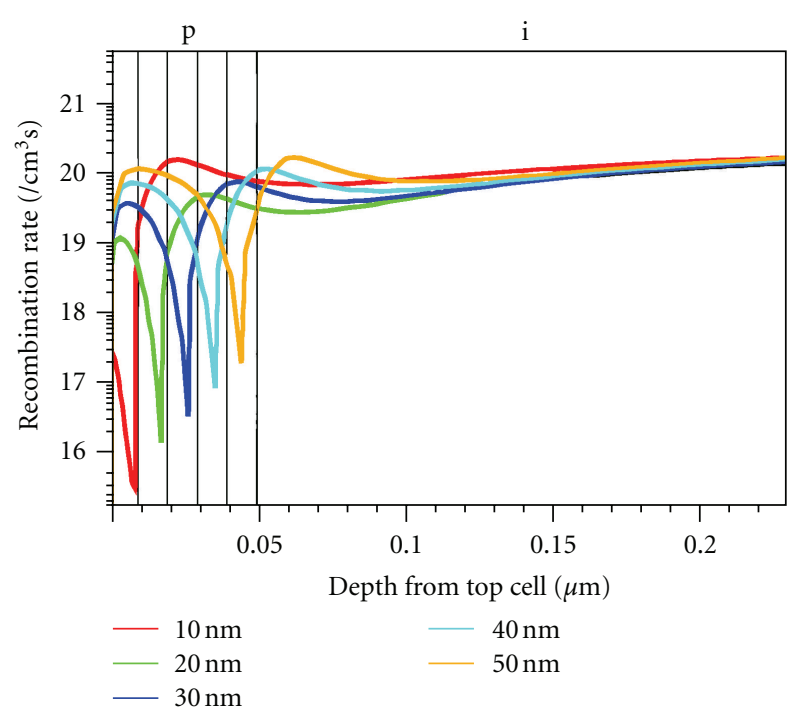

(b)

FIGURE 7: Photogeneration rate and recombination rate of The aSiGe:H solar cell device for different thickness of p-layer.

current density, open-circuit voltage, maximum output power, and fill factor of $267 \mathrm{~A} / \mathrm{m}^{2}, 1.13 \mathrm{~V}, 235 \mathrm{~W} / \mathrm{m}^{2}$, and 0.795 are obtained, respectively.

\section{Conclusion}

A two-dimensional computer simulation is presented here using the standard continuous density of state model for deep and shallow states in amorphous silicon band-gap for the optimization of the single- and double-junctionhydrogenated amorphous Silicon-Germanium solar cells. The simulation and modeling process indicate that it is possible to optimize the solar cell performance and improve the efficiency of the cell by appropriate selection of the thickness and doping concentration of the layers. 


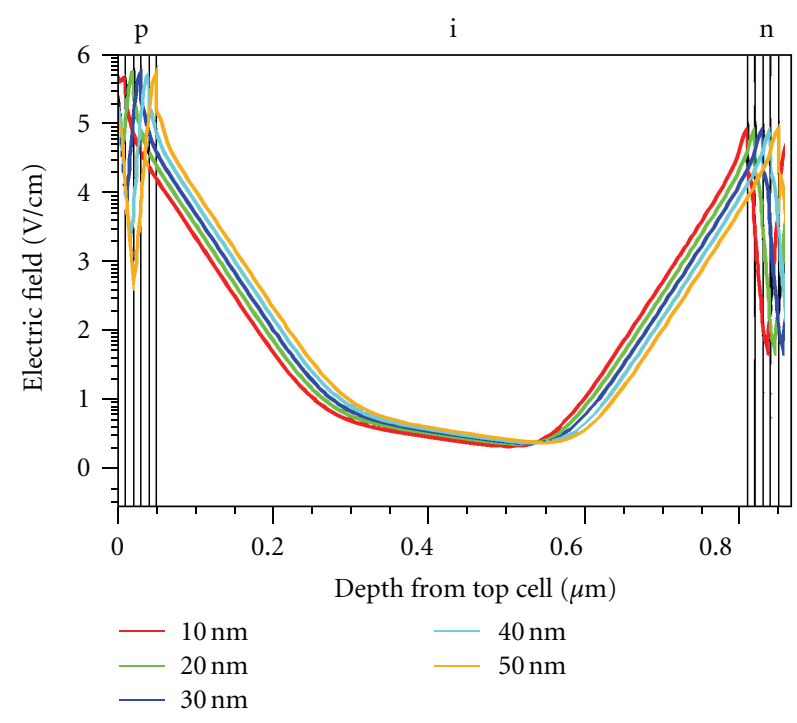

FIGURE 8: Electric field distribution of The a-SiGe:H solar cell device for different thickness of $\mathrm{p}$-layer.

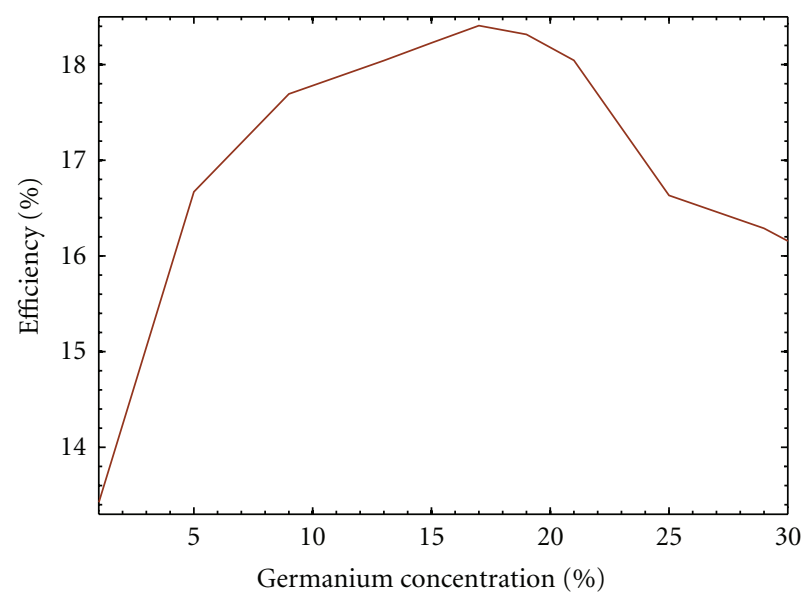

Figure 9: The a-SiGe:H solar cell efficiency as a function of Ge concentration in SiGe layer.

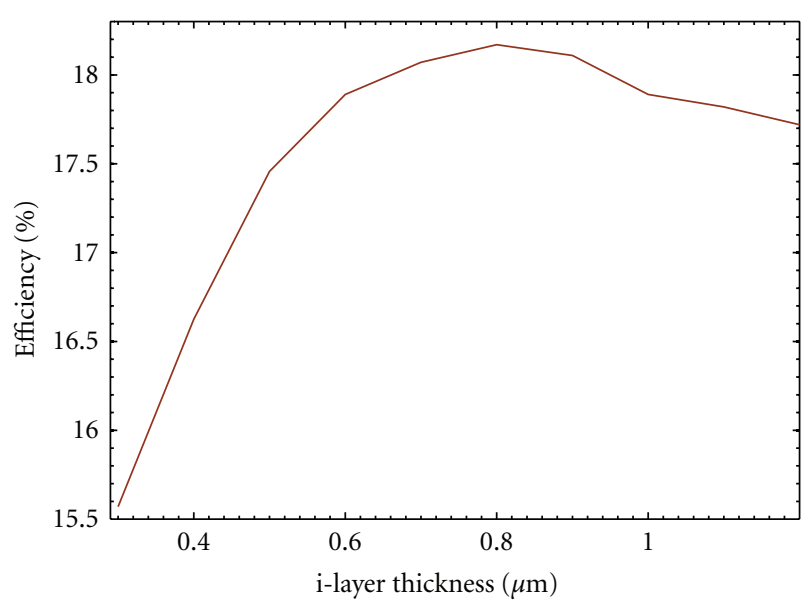

Figure 10: The a-SiGe:H solar cell efficiency as a function of i-layer thickness.

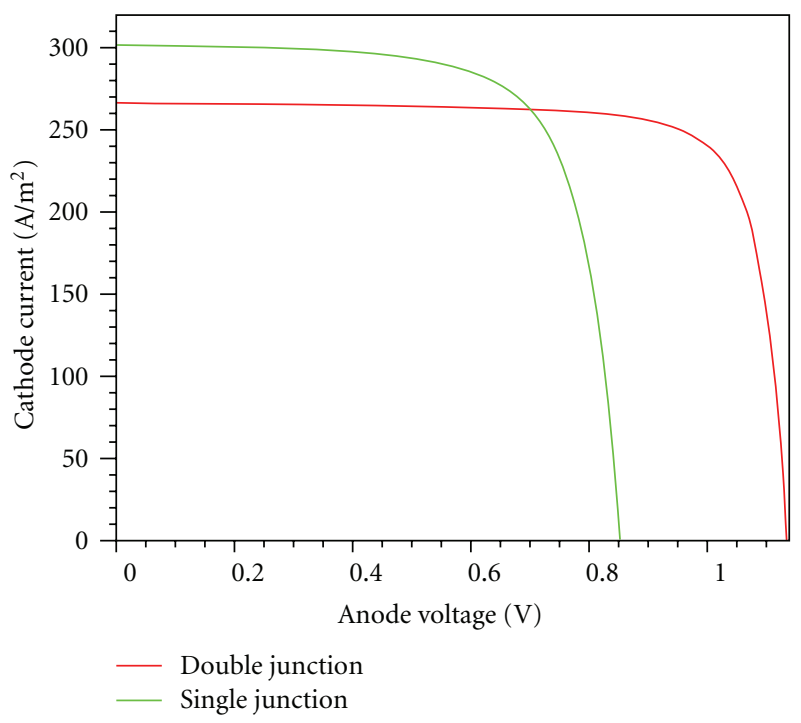

(a)

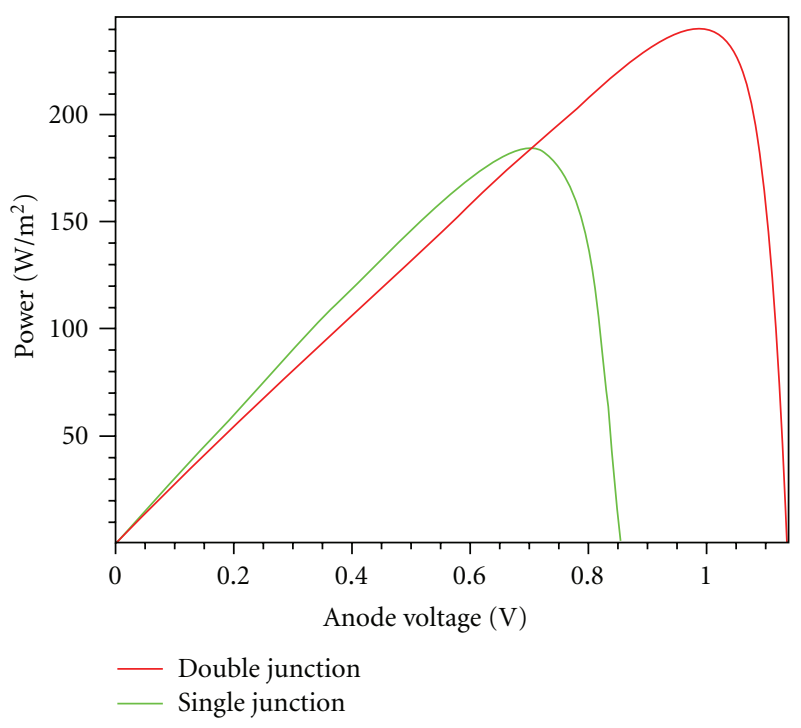

(b)

FIGURE 11: $I-V$ and $P$ - $V$ curves of the optimized single- and doublejunction solar cells.

\section{Acknowledgments}

This work was partly supported by Khuzestan Regional Electricity Company and Jundishapour Water and Energy Research Institute, Iran.

\section{References}

[1] A. Gordijn, R. J. Zambrano, J. K. Rath, and R. E. I. Schropp, "Highly stable hydrogenated amorphous silicon germanium solar cells," IEEE Transactions on Electron Devices, vol. 49, no. 5, pp. 949-952, 2002.

[2] S. Guha and J. Yang, "Science and technology of amorphous silicon alloy photovoltaics," IEEE Transactions on Electron Devices, vol. 46, no. 10, pp. 2080-2085, 1999. 
[3] A. Banerjee, K. Hoffman, X. Xu, J. Yang, and S. Guha, "Back reflector texture and stability issues in high efficiency multijunction amorphous silicon alloy solar cells," in Proceedings of the IEEE 1st World Conference on Photovoltaic Energy Conversion, vol. 1, pp. 539-542, Waikoloa, Hawai, USA, 1994.

[4] M. H. Liao and C. H. Chen, "The investigation of optimal Sisige hetero-structure thin-film solar cell with theoretical calculation and quantitative analysis," IEEE Transactions on Nanotechnology, vol. 10, no. 4, pp. 770-773, 2011.

[5] C. Lee, H. Efstathiadis, J. E. Raynolds, and P. Haldar, "Twodimensional computer modeling of single junction a-Si:H solar cells," in Proceedings of the 34th IEEE Photovoltaic Specialists Conference, (PVSC '09), pp. 001118-001122, Philadelphia, $\mathrm{Pa}$, USA, June 2009.

[6] Z. Q. Li, Y. G. Xiao, and Z. M. S. Li, "Modeling of multi-junction solar cells by Crosslight APSYS," in Proceedings of the High and Low Concentration for Solar Electric Applications.

[7] A. Kosarian and P. Jelodarian, "Optimization and characterization of advanced solar cells based on thin-film a-Si:H/SiGe hetero-structure," in Proceedings of the 19th Iranian Conference on Electrical Engineering, (ICEE '11), pp. 1-5, 2011.

[8] H. Tasaki, W. Y. Kim, M. Hallerdt, M. Konagai, and K. Takahashi, "Computer simulation model of the effects of interface states on high-performance amorphous silicon solar cells," Journal of Applied Physics, vol. 63, no. 2, pp. 550-560, 1988.

[9] M. Kemp, M. Meunier, and C. G. Tannous, "Simulation of the amorphous silicon static induction transistor," Solid State Electronics, vol. 32, no. 2, pp. 149-157, 1989.

[10] M. Hack and J. G. Shaw, "Numerical simulations of amorphous and polycrystalline silicon thin-film transistors," in Proceedings of the Conference on Solid State Devices and Materials, pp. 999-1002, Sendai, Japan, 1990. 


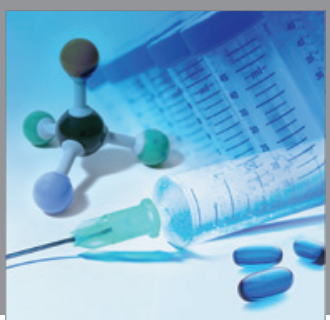

International Journal of

Medicinal Chemistry

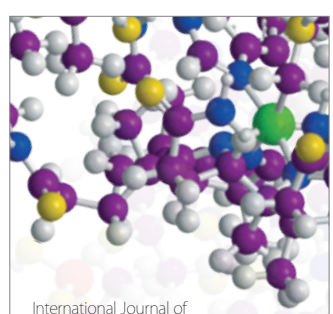

Carbohydrate Chemistry

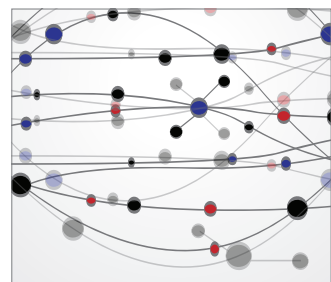

The Scientific World Journal
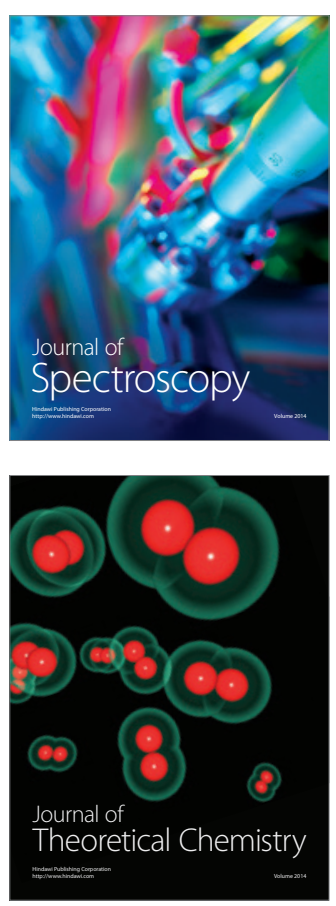
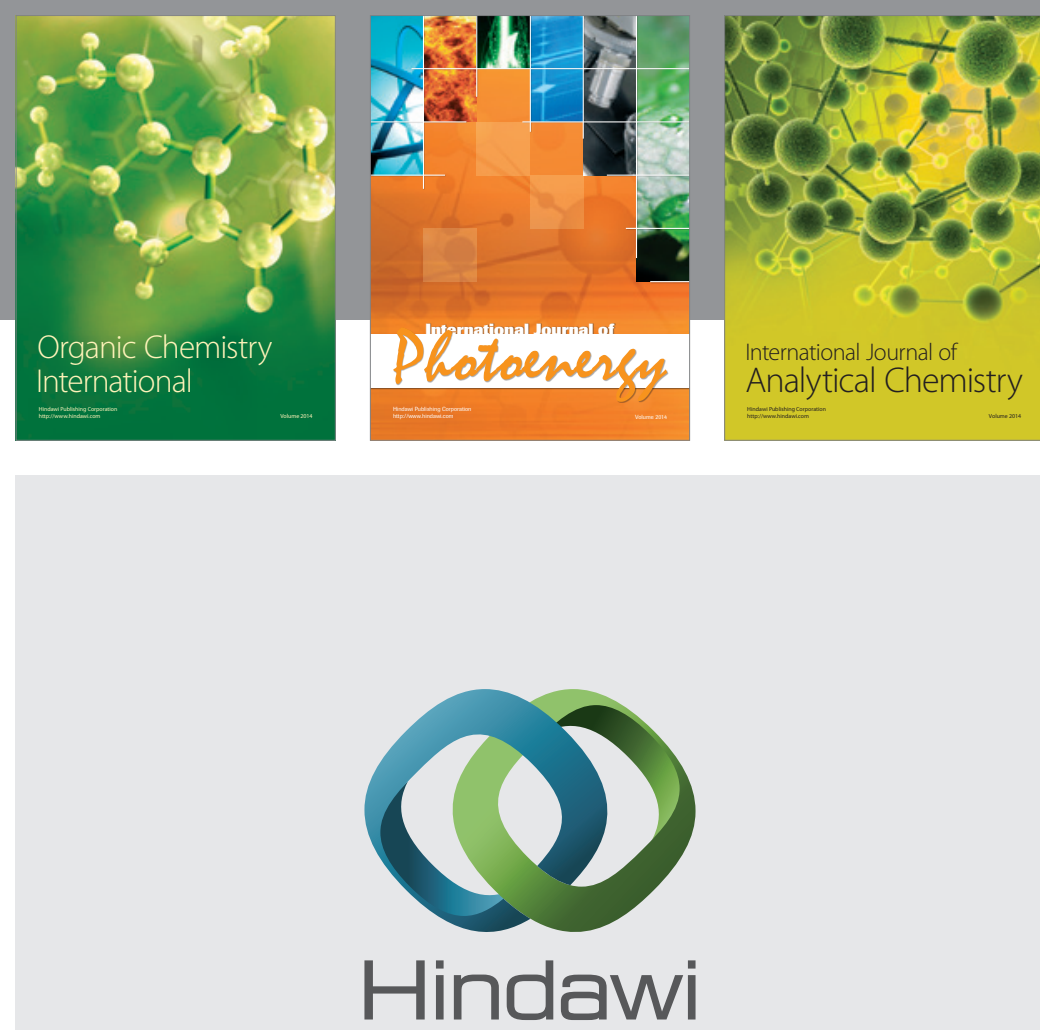

Submit your manuscripts at

http://www.hindawi.com
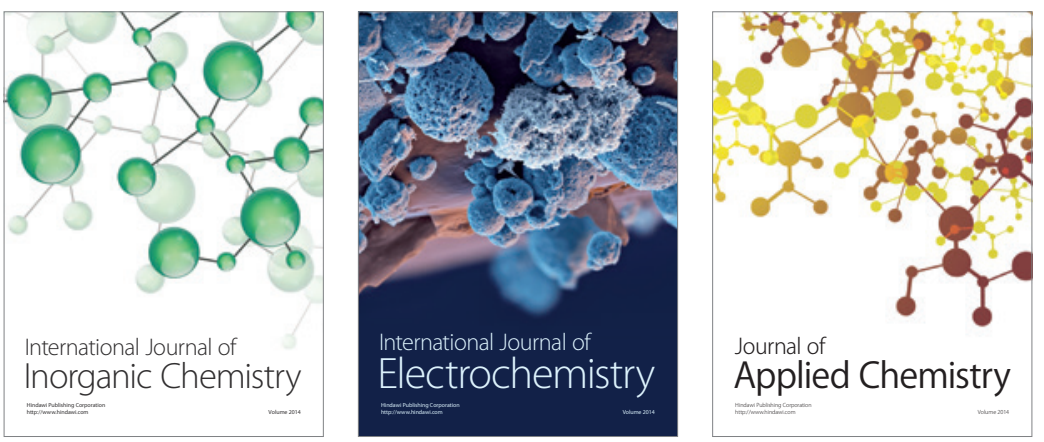

Journal of

Applied Chemistry
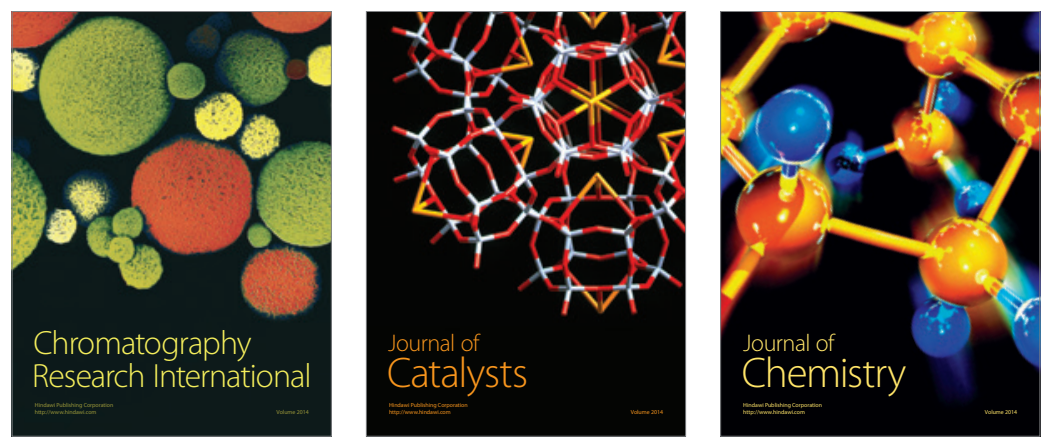
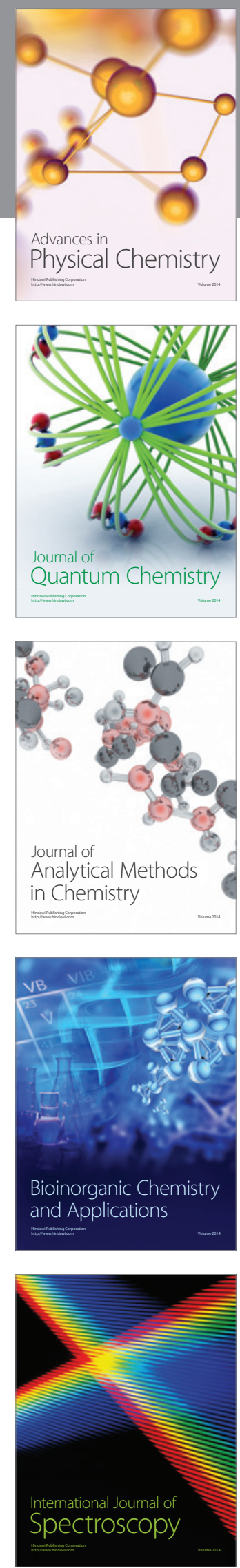